\title{
A dimensão revolucionária do desenvolvimento e o papel da imaginação
}

\author{
The revolutionary dimension of development and the role of \\ imagination
}

Vera Lucia Trevisan de Souza ${ }^{1}$

Guilherme Siqueira Arinelli²

\begin{abstract}
RESUMO
Este artigo, de natureza teórico-reflexiva, tem por objetivo problematizar o tema do desenvolvimento na Psicologia HistóricoCultural, assumindo-o como revolucionário. A partir de estudos e reflexões apresentamse compreensões que colocam a imaginação no centro do processo revolucionário empreendido pelo sujeito ao longo de sua vida. Ao final, defende-se, a partir de estudos promovidos com estudantes e profissionais de instituições educativas, a proposição da pesquisa-intervenção como método de investigação e ação que põe o fenômeno do desenvolvimento em movimento e possibilita apreendê-lo.
\end{abstract}

Palavras-chave: Desenvolvimento; Imaginação; Psicologia Histórico-Cultural.

\begin{abstract}
This paper - of theoretical and reflexive nature - aims to problematize the theme of development in Cultural-Historical Psychology assuming it as revolutionary. Based on studies and reflections, it presents understandings that situate imagination at the center of the revolutionary process undertaken by the subject throughout his life. Finally, this paper defends, recurring to studies developed with students and professionals of educational institutions, the proposal of interventionresearch as a method of investigation and action that puts the phenomenon of development in motion and makes it possible to apprehend it.
\end{abstract}

Keywords: Development; Imagination; Cultural-Historical Psychology.

\section{Introdução}

Falar em desenvolvimento da perspectiva da Psicologia Histórico-cultural implica situá-lo na matriz do materialismo histórico-dialético à qual se filiam os conceitos e proposições de Vigotski e seus estudiosos sobre o psiquismo humano. Essa condição demanda analisar o desenvolvimento como relacionaldesenvolvimental, ou seja, tomá-lo como em permanente processo, movendo-se em várias direções, e considerar as diferentes dimensões/conceitos que o constituem.

\footnotetext{
${ }^{1}$ Docente e pesquisadora do Programa de Pós-graduação Stricto Sensu em Psicologia e do curso de graduação em Psicologia da Pontifícia Universidade Católica de Campinas, Brasil. E-mail: vera.trevisan@uol.com.br.

${ }^{2}$ Doutorando pelo Programa de Pós-graduação Stricto Sensu em Psicologia da Pontifícia

Universidade Católica de Campinas, Brasil. E-mail: gsarinelli@gmail.com.
} 
Dessa perspectiva, é possível se manter fiel ao que preconiza Vigotski ao não considerar o desenvolvimento, em nenhum momento, como consolidado ou concluído, mas se consolidando. Ao avançar nesse movimento, abrem-se novas possibilidades de domínio, que por sua vez dão origem a novos desenvolvimentos, sustentados nos anteriores que, por sua vez, continuam a existir dando condições a novas formas de ser, pensar e agir.

O desenvolvimento só pode ser pensado, estudado e analisado no sujeito que se desenvolve, considerando-se suas forças motrizes, direções principais e características específicas - do sujeito e do contexto - no processo de assunção a novos modos de funcionar. Ele exige, portanto, a ação do sujeito.

Partindo dessas acepções, o artigo que ora se inscreve, de natureza teóricoreflexiva, tem por objetivo problematizar o tema do desenvolvimento tomando-o como revolucionário, de modo a ampliar o diálogo com outros estudiosos em torno desta compreensão. Para tal, organiza-se nos seguintes tópicos: problematização da ideia de desenvolvimento em Vigotski e seu lugar em sua produção teórica de base materialista-dialética; discussão da dinâmica do desenvolvimento e do funcionamento das Funções Psicológicas Superiores: perejivânie 3 e situação social de desenvolvimento; proposição do papel da imaginação no desenvolvimento; problematização da pesquisa em desenvolvimento e considerações sobre métodos de investigação e, por fim, um breve relato de uma experiência de pesquisaintervenção em que se busca compreender o processo imaginativo na promoção do desenvolvimento de adolescentes.

\section{A questão do desenvolvimento na teoria de Vigotski: fundamentando algumas compreensões}

Todos os limites que existem, existem só e simplesmente para que sejam ultrapassados (NOVALIS, 1798-1799, p. 81, apud LAPOUJADE, 1988, p. 07).

Como anunciado na introdução, este artigo não pretende abordar o desenvolvimento humano como campo de estudos para além da psicologia,

\footnotetext{
${ }^{3}$ Utilizaremos nesse texto a grafia "perejivânie" para o termo em russo por compreender que esta se apresenta como a opção mais adequada à língua portuguesa.
} 
tampouco apresentar uma revisão do que tem sido discutido sobre desenvolvimento no campo da psicologia em suas diferentes abordagens. Busca, à guisa de aproximações e reflexões, adensar a problemática do desenvolvimento tal como é ou deveria ser compreendido a partir das proposições de teóricos da Psicologia Histórico-Cultural, sobretudo Vigotski, um de seus principais representantes.

As ideias aqui apresentadas assumem especificidade maior por abordar uma compreensão do desenvolvimento que deriva de anos de estudos desse teórico, buscando dialogar com suas bases epistemológicas e ontológicas e suas definições do psiquismo humano. $\mathrm{O}$ estudo do conjunto da obra do autor, focalizando a relação entre conceitos e acepções na definição de um homem que figura sempre como criativo e transformador, perscrutando ideias não explicitadas claramente, mas implícitas nos modos de acercamento do fenômeno humano pelo autor e no diálogo permanente com tantos estudiosos da teoria - hoje objeto de investigação de campos diversos, próximos ou mais distantes da psicologia - permite, sem dúvida, qualificar o desenvolvimento humano segundo a compreensão de Vigotski como revolucionário.

Cabe, então, explicitar as bases e a lógica em que se assenta essa compreensão: por que entendemos, a partir de Vigotski, o desenvolvimento como revolução? A ciência psicológica construída pelo autor, que se sustenta epistemologicamente no materialismo dialético, instala o antagonismo no centro do funcionamento psicológico e faz da contradição a principal característica de seu dinamismo. Esse dimensionamento do psiquismo já pressupõe o movimento que está na base de sua constituição, e o qualifica como não linear, influenciado por múltiplos fenômenos e se encaminhando para várias direções, que avançam e retrocedem ao longo da vida do sujeito.

Para Vigotski, então, só faz sentido olhar para o desenvolvimento no sujeito, compreendido como autor e principal responsável por sua constituição como processo único e sui generis que vai se consolidando em uma história de recursividade e superação. Ocorre que ele nunca se consolida, mas a cada nova conquista na qualidade de funcionamento de determinada função, por exemplo, abrem-se novas possibilidades de apropriação, em um movimento permanente que não finda. O que isso significa? O modo como Vigotski concebe o desenvolvimento 
no sujeito tem no centro a historicidade enquanto processo que incorpora o consolidado, transformando-o e consolidando-se, o que, por sua vez, gera um novo consolidado/consolidando-se como unidade dialética. E as direções nesse processo são múltiplas, visto que a nova qualidade não significa melhor ou mais avançada, mas nova mediação, ou seja, abertura ao novo.

Essas perspectivas epistemológica e ontológica demandam que se considere a sociogênese, pois ela está na base da explicação do desenvolvimento enquanto processo infindável de constituição do sujeito. Para Vigotski (1935/2010), o meio é fonte de desenvolvimento, pois porta a cultura cujo acesso é o que possibilita a ascensão das funções psicológicas à qualidade de superiores. Superior porque mediada justamente pela cultura enquanto produção humana, e processo no qual o sujeito atua produzindo significações ao vivido e se apropriando dessas significações que passam a constituir o seu psiquismo que, por sua vez, se abre a novas significações que se originam das interações do sujeito com os outros da cultura.

Como ocorre esse processo na relação com o social? No âmbito do desenvolvimento, o momento mais importante é quando a criança começa a significar, ou seja, criar e se utilizar de signos. E os signos são produção humana presentes na cultura, significados pelos outros da interação que, no processo de conversão à dimensão intrapsicológica também são internalizados. Ou seja, além das significações, o modo como o outro da relação age e se relaciona no contexto de significações é apropriado pelo sujeito (VIGOTSKI, 1931/1995). Cabe explicitar melhor a dinâmica de funcionamento deste processo, o que faremos no próximo item.

\section{A dinâmica do desenvolvimento: funções psicológicas superiores, perejivânie e} situação social de desenvolvimento

É possível afirmar que a característica mais fundamental da experiência humana é sua capacidade de produzir significações justamente pelo caráter mediado do funcionamento psicológico denominado por Vigotski (1931/1995) como superior ou culturalizado. Essa capacidade, que está na base do processo de 
constituição do sujeito, se exerce em uma dimensão interacional entre sujeito e meio via processo de negociação permanente.

Negociação repleta de ambivalências e resistências. Ou seja, o sujeito resiste: ao que lhe é apresentado como situação ou fato, às "sugestões sociais" de acordo com a significação que atribui à experiência, em uma atuação do psiquismo que Veresov (2017), tomando emprestado um conceito da Física, define como prisma, que equivale a um filtro por onde passa o que tem sentido e significado para o sujeito, por onde não passa o que ele recusa e ainda como processo no qual o sujeito subverte a experiência, convertendo-a em compreensão própria. Logo, a estrutura das funções e suas características não mudam, mas sim suas relações, que se ampliam infinitamente, em um movimento constante que não cessa. Esta é a compreensão do autor para perejivânie ${ }^{4}$, unidade do desenvolvimento, segundo Vigotski (1930-1934/1996), justamente por se constituir pela incorporação do meio resultando no que denomina de Situação Social de Desenvolvimento [SSD] ${ }^{5}$.

Entendemos perejivânie como a unidade da relação consciência-meio em eventos dramáticos, caracterizado pela colisão entre os desejos e motivos do sujeito e a demanda de dada situação ou fenômeno do meio. Colisão que produz conflitos que suscitam novas relações entre as funções psicológicas superiores, resultando, portanto, em desenvolvimento. Daí a compreensão de perejivânie como evento dramático que muda o curso do desenvolvimento (SOUZA; DUGNANI; REIS, 2018).

Para Vigotski (1935/2010), a perejivânie, que pode ser compreendida como experiência carregada de fortes emoções, é unidade da personalidade por envolver, enquanto vivência, todas as dimensões psíquicas constituintes do sujeito e as situações nas quais tal experiência se efetiva. A essas situações dá o nome de Situação Social de Desenvolvimento, que seriam condições para essa experiência

\footnotetext{
4 Tendo em vista a existência de várias produções dedicadas à discussão e explicitação do conceito de perejivânie em Vigotski, só para citar alguns: número especial da revista Mind, Culture, and Activity, vol. 23, no. 4, de 2016; e livro editado pela Springer em 2017 - Perezhivanie, emotions and subjectivity: advancing Vygotsky's legacy, com artigos e capítulos de estudiosos do mundo todo; não aprofundaremos a discussão sobre o conceito. Contudo, o tomamos como mais um fundamento do desenvolvimento como revolução.

${ }^{5}$ Veresov (2017) faz uma diferenciação entre situação social e situação social de desenvolvimento que nos parece interessante: toda situação é social, mas não necessariamente SSD. Para que uma situação social se constitua em SSD, portanto, em promotora de perejivânie e o consequente desenvolvimento, é necessário que se intervenha nela, observando o que desafia o sujeito a avançar.
} 
qualificada, promotora de desenvolvimento, da mudança de seu curso, no sentido da abertura a novas possibilidades de ser do sujeito.

É desta forma que o psiquismo se constitui pelo que é vivido com significações próprias, que incluem o social, sua experiência, as emoções presentes naquela experiência, o modo como é afetado por elas, enfim (TATEO, 2016).

Desta perspectiva, o desenvolvimento pode ser pensado como drama, como devir, como processo dialético permanente. E só é devir - aberto - porque simulado, qualidade de funcionamento possível pela via da imaginação, conforme se apresentará no próximo tópico.

\section{A dimensão transgressora e libertadora da imaginação no desenvolvimento}

O homem se conquista como humano pelo quanto é capaz de efetuar à perfeição o movimento dialético de antagonismo e harmonia em uma sucessão sem fim. Movimento que lhe oferece infinitas possibilidades, sobretudo quando se desdobra no campo do "como se" que expressa a duplicidade; a rigor, o desdobramento aberto da simulação. A ficção imaginativa abre um horizonte infinito ao humano "como se" (LAPOUJADE, 1988, p. 214, tradução livre).

A epígrafe que abre este tópico anuncia a dimensão epistemológica que a imaginação assume no desenvolvimento humano, da perspectiva que aqui defendemos: o desenvolvimento como revolução. Escrita por María Noel Lapoujade, em seu livro Filosofía de La Imaginación, de 1988, bem poderia ser parte da definição de Vigotski (1930/2009) sobre a imaginação como Função Psicológica Superior. Compreensão que também anuncia a dimensão ontológica da imaginação: ela torna possível - ainda que não exclusivamente - que o homem se torne humano; ou seja, está na base do seu funcionamento psicológico.

Arriscamos afirmar que a função primordial do desenvolvimento revolucionário, segundo o preconizado na obra de Vigotski, é a imaginação. Isto porque a imaginação é uma função de substituição (“como se”) e a forma humana mais plena de substituição é a simbolização. Simbolização que é marca do humano, segundo Cassirer (1977), "Entre o sistema receptor e o sistema de reação (presente em todos os animais) encontramos no homem um terceiro elo - o sistema simbólico" (p. 49). 
Ou seja, produções como a linguagem, o mito, a arte, a ciência e a religião são condições da vida humana que constituem os fios que tecem a rede simbólica em que ele vive e, ao mesmo tempo em que a toma como condição de vida produz essa mesma condição com novos e infinitos símbolos, em um processo dialético e permanente. Ainda nas palavras do autor: "a realidade física parece retroceder proporcionalmente, a medida que avança a atividade simbólica do homem" (CASSIRER, 1977, p.50)

O homem, então, deixaria de lidar com as próprias coisas para conversar consigo próprio. Ou seja, qualquer conhecimento da realidade passa pelo pensamento humano e, envolvido com a rede simbólica - só pode ver através dela, como um modo mediado de acessar a realidade que o liberta da prisão do empírico.

Simbolizar, portanto, envolve, conforme destaca Lapoujade na epígrafe deste tópico, a substituição de algo por outro - símbolo, ou seja, tomar o símbolo "como se" fosse o objeto real. E é a substituição, o "como se" que caracteriza a atividade de imaginar. Se o homem é um "ser simbólico", como já afirmava Cassirer (1977), e o desenvolvimento do sujeito se processa no movimento dialético/revolucionário de conversão da cultura apropriada das relações intersubjetivas para a dimensão intrassubjetiva, via mediação, então é possível dizer que sem imaginação não há mediação possível, pois a própria intersubjetividade só se institui por sua via. Assim compreendida, a imaginação é a matriz na qual se desenvolvem outras funções e processos do psiquismo humano.

Esse processo teria como dinâmica a reprodução de atos e pensamentos humanos, em suas infinitas formas dialéticas que envolvem a identificação e a não identificação enquanto limites do eu, que pensa, age no limite do eu e do não-eu, visto que mesmo agindo "como se fosse" o outro (quando imagina o que o outro estaria sentindo ou pensando, do que gostaria que pensasse, o que entenderia do que diz), não deixa de ser si mesmo (eu), justamente por construir significações sobre esta relação, as quais nortearão suas ações e pensamentos. E isso em um movimento de antagonismos e harmonia, que se caracteriza como tensão permanente justamente pelas possibilidades (os "como se") sempre abertas.

É pela via da imaginação que o homem pode gerar relações espaço-temporais novas, viver experiências sem nunca ter transitado em determinado tempo ou 
estado em certos lugares. E esta é uma dimensão libertadora do ato de imaginar. Neste sentido, tempo e espaço se convertem em dominados, submetidos à vontade do sujeito, que ganharia autonomia de ação e pensamento (LAPOUJADE, 1988). Seria possível, então, pensar a autonomia como lógica da imaginação, pois estruturaria sua produção e cuja plenitude seria alcançada em sua função criadora, organizadora de outros mundos, outros tempos-espaços.

Enquanto função psicológica superior, a imaginação assume prevalência na aprendizagem, na apropriação de conhecimentos complexos, logo, no desenvolvimento revolucionário. Isto porque, o domínio de conhecimentos de natureza complexa amplia imensamente as relações entre as funções psicológicas superiores, conferindo qualidade superior ao funcionamento do sistema psicológico que amplia as possibilidades de pensamento e ações do sujeito (SOUZA, 2016).

A imaginação, nos processos de conhecimento, dota as atividades abstratas de reflexão, de imagens que configuram os conceitos, que aludem a eles mediante símbolos, em um processo em que o "como se" se exercita permanentemente. Ou seja, os processos reflexivos, tão caros ao desenvolvimento revolucionário, se enriquecem com a ação da imaginação. Isto porque, sua atividade pode unir e separar livremente os fatos ou conhecimentos, anexar ou isolar os eventos, espacial ou temporalmente.

Essas acepções assumem grande relevância para se pensar as práticas pedagógicas desenvolvidas no interior das escolas. Qual o lugar da imaginação? O que sabem os professores sobre os processos imaginativos e as ações que os promovem?

Em síntese, simbolização é um trabalho da imaginação, e simbolizar é uma de suas funções. Essa duplicidade que envolve a imaginação e se situa na raiz do humano ratifica o caráter dialético que está na base do desenvolvimento revolucionário, que envolve movimentos de fusão e distanciamento na construção da singularidade possível na relação universal-particular-singular. A atividade da imaginação aflora em diversas formas de oposição consistentes, em processos de negação (separação) - identificação (união); estruturação-desestruturação; limitação-transgressão. Isto porque a imaginação se mostra como uma atividade contraditória, em que gera movimentos opostos que coexistem. Seu trabalho se 
manifesta ao colocar os limites do eu e ao mesmo tempo derrubá-los em atos de transgressão. Neste sentido, ela impõe limites ao eu, ao mesmo tempo em que o liberta. Logo, a imaginação é atividade complexa de afirmação-negação. E sua atividade de transgressão se realiza na medida em que aponta o futuro estendendo os momentos do eu no tempo. E sua característica transgressora se afirma na atividade de ultrapassar limites.

O papel da imaginação no psiquismo é ainda mais complexo de dimensionar, vista sua centralidade na mediação das funções psicológicas superiores, promovendo nexos que abrem novas possibilidades de funcionamento do sistema psicológico. Desta perspectiva ela é atividade mediada e mediatizante, atuando no dimensionamento temporal - passado e futuro - presente e devir. Pode, também, produzir relações de síntese do percebido pelo sujeito e dos entendimentos que derivam dessa percepção, resultando em conceitos, processo possível graças à dupla ação operada pela imagem que proporciona a concreção figurativa dos conceitos e a generalidade abstrata do percebido.

Vigotski (1930/2009) já chamava a atenção para o importante papel desempenhado pela imaginação no psiquismo humano. Segundo o autor, ainda que a matéria básica da imaginação seja a experiência do sujeito, sua dinâmica consiste em permitir-lhe extrapolar a realidade vivida empiricamente justamente para criar outras experiências pela via da imaginação. Essa acepção revela o caráter dialético da imaginação para o autor e sua importância na relação com as outras funções psicológicas superiores na reorganização do psiquismo, que assume nova qualidade justamente a partir da criação dessas novas experiências - pensadas, refletidas, sentidas, acessadas empiricamente ou virtualmente. Seria esse movimento que justificaria as diferenças do funcionamento da imaginação em diferentes momentos do desenvolvimento.

Tomando como exemplo a adolescência, público ao qual nossos estudos têm se voltado nos últimos anos, Vigotski (1930-1934/1996) vai defender que é em decorrência das experiências vividas que a imaginação na adolescência se diferencia daquela disponível na infância, quando a imaginação tem como matéria os objetos concretos, sendo deles dependente, enquanto na adolescência sua fonte é simbólica, e a linguagem e as imagens assumem prevalência. O autor destaca 
que, na infância, a imaginação se objetiva nas brincadeiras de faz-de-conta, por exemplo; já na adolescência, a imaginação se objetiva na construção de textos e imagens que, por vezes, afastam o jovem da atuação na realidade mais imediata (VIGOTSKI, 1930-1934/1996).

É justamente esse modo de funcionamento da imaginação descrito por Vigotski, como ocorrendo na adolescência, que permite o acesso do jovem a situações e emoções ainda não experimentadas por ele, gerando novas significações e compreensões sobre o mundo e si próprio. E ao se afastar das práticas cotidianas, o sujeito se liberta por meio das novas relações que se instituem às funções psicológicas superiores, de natureza mais reflexiva e menos pragmática (VIGOTSKI, 1930-1934/1996).

Ainda que a imaginação esteja na base de todas as funções psicológicas superiores, quando se aborda o desenvolvimento revolucionário há que se destacar o seu papel no desenvolvimento do pensamento por conceito, função psicológica que permite ao sujeito ampliar, sobremaneira, seu modo de compreensão e ação no mundo, resultando nas possibilidades de um posicionamento e de uma compreensão mais ampliada da realidade.

Tal funcionamento, caracterizado pela capacidade de compreender não somente o que se faz/pensa como também o porquê do que se faz/se pensa, é que dá ao sujeito o conhecimento das causas (ESPINOSA, 1677/1957), condição para se libertar da submissão, do padecimento, e criar potência de ação. Radica nessa compreensão a importância de pensamentos com essa qualidade de funcionamento na promoção do desenvolvimento, entendido como revolucionário. Pois também é o pensamento por conceito que aciona a imaginação a avançar em complexidade, aprofundando-se, adensando-se pelo emprego do "como se", afastando-se da realidade em consonância aos limites do eu, conforme postula Lapoujade (1988).

Então, é possível afirmar que a relação com o pensamento por conceitos é uma das principais funções da imaginação no desenvolvimento, visto ser ela, por um lado, condição ao mesmo, responsável pela operação de funções mais complexas e, por outro, dependente do pensamento complexo para alçar novos voos no mundo do "como se", caracterizando uma dinâmica que constitui o psiquismo enquanto sistema. Na adolescência, quando o sujeito se encontra em transição no que 
concerne aos seus interesses, desejos, possibilidades e recursos mentais, não só a memória e o pensamento são cruciais ao seu desenvolvimento, mas também, e principalmente, a imaginação e os processos criativos.

Uma última consideração que queremos trazer neste tópico diz respeito à relação da imaginação com a emoção. Para Vigotski (1930/2009), a emoção teria dupla função: estimular a imaginação; e fazer dela um meio para sua expressão ou realização. Radica nesta compreensão, de natureza epistemológica, a razão para utilizarmos a arte em nossas pesquisas e ações na escola, conforme será apresentado no último tópico.

Conforme já apontamos em outro artigo, a imaginação e seu enlace com a emoção são evidenciados no processo de apreciação/contemplação de uma expressão artística, razão que nos conduz a tomar a arte como instrumento psicológico que favorece o desenvolvimento revolucionário:

Nesse processo, a emoção passa a se servir da imaginação, para representar, em imagens, os afetos, sendo portanto vivida duas vezes, e por isso chamada de coemoção. A coemoção é o elo primordial entre a imaginação e a emoção, porque permite ao sujeito ampliar suas vivências. Ao entrar em contato com as narrativas das obras de arte, o seu repertório se amplia, porque pode experienciar algo para além de sua vida vivida, no âmbito do humano-genérico. Esse movimento entre emoção e significação mediado pela imaginação, que é produzido pela contemplação de uma obra de arte, promove a transformação da intensidade, da frequência e da expressão das emoções, possibilitando sua ressignificação e, em decorrência, sua transformação (SOUZA; DUGNANI; REIS, 2018, p.380).

\section{A pesquisa-intervenção: proposição ao estudo do fenômeno do desenvolvimento}

\section{do sujeito}

O desenvolvimento, conforme vimos apresentando neste artigo, é um fenômeno de grande complexidade que exige estudos permanentes. Estudiosos que assumem a perspectiva teórico-metodológica da Psicologia Histórico-cultural têm empreendido em debates e proposições acerca de como deveriam ser os procedimentos investigativos capazes de apreender ou de se aproximar desse fenômeno que, Vigotski, em 1931, já definia como: 
[...] Um complexo processo dialético, que se distingue por uma complicada periodicidade, pela desproporção no desenvolvimento das diversas funções, pela transformação qualitativa de umas Funções em outras, um entrelaçamento complexo de processos evolutivos e involutivos, pelo complexo cruzamento de fatores externos e internos e por um complexo processo de superação de dificuldades e de adaptação. (1931/1995, p. 141, tradução e grifos nossos).

$\mathrm{Na}$ compreensão do autor, a tomar pelo número de vezes que a palavra "complexo" aparece em sua definição, evidencia-se a imensa tarefa que constitui sua compreensão e investigação. Vigotski (1931/1995) apresenta esta definição de desenvolvimento justamente quando está discorrendo sobre a gênese das funções psicológicas superiores, colocando em pauta os métodos de investigação. Faz uma crítica aos métodos desenvolvidos até então, que teriam como foco as peculiaridades negativas do desenvolvimento, comparando a criança com o adulto ou a criança "normal" com a "anormal". Ele defende que se olhe para a criança "inteira", "real", em sua plenitude e riqueza e dar a ver o que emerge como positivo de sua personalidade (p.141).

Assim, ao problematizar os métodos de investigação do desenvolvimento, Vigotski assevera que seu estudo deve ter como objeto o sujeito que se desenvolve, que é o autor e ator do processo que se busca estudar. E, ao definir o desenvolvimento como processo de evoluções e involuções que se entrelaçam de modo complexo, que cruzam fatores internos e externos para a superação de dificuldades deixa claro, a nosso ver, o caráter revolucionário do desenvolvimento e ratifica o quão difícil é seu estudo, porém, já indica mudanças fundamentais nos procedimentos metodológicos de investigação dos processos eminentemente humanos.

Deriva desta concepção a proposição de que não se deve olhar para o resultado/produto do desenvolvimento, mas ao seu processo para chegar a conhecer como o que se manifesta como produto chegou a ser o que é. Esta compreensão demanda construir procedimentos investigativos que coloquem o fenômeno investigado em movimento.

Reconhecemos a complexidade envolvida nos estudos do desenvolvimento nessa perspectiva teórico-epistemológica. Entretanto, aprofundar aqui a discussão a esse respeito fugiria aos objetivos propostos, ainda que seja necessário admitir a 
necessidade de se empreender esse esforço e nos propomos a fazê-lo em outra oportunidade. Por hora, nos deteremos em apresentar, brevemente, as dimensões que necessitam ser consideradas nos estudos sobre o desenvolvimento revolucionário partindo da definição de Vigotski que abre este tópico para, em seguida, falar brevemente da pesquisa-intervenção e nos encaminhar à conclusão do texto.

A perspectiva epistemológica a que se filiam as ideias de Vigotski é o marxismo, do qual, conforme declara o autor, muito lhe interessa o método. $\mathrm{O}$ materialismo Histórico-Dialético parece fazer todo sentido como matriz metodológica quando retornamos à definição de desenvolvimento: o foco no processo que remete à historicidade do fenômeno, o sujeito concreto como objeto de investigação que vive o processo e o objetiva, dá materialidade ao fenômeno investigado, e as diversas dimensões, condições que se imbricam no desenvolvimento como interno/externo, adaptação/superação, função consolidada/se consolidando, que reportam sua característica dialética.

Começando pela característica dialética do desenvolvimento, ela nos impõe que olhemos várias dimensões em relação, ou seja, o que caracteriza a dialética é o movimento que só pode ser apreendido nas relações, no caso, entre mais de um dos aspectos do desenvolvimento. Que aspectos seriam esses? Retomando a definição de desenvolvimento de Vigotski, é possível derivar como aspectos do desenvolvimento que devem ser focalizados na investigação: suas fontes, suas forças motrizes, suas direções principais, as características específicas do sujeito e os aspectos que emergem como resultados ou pontos de chegada. A depender do que se busca com o estudo, pode-se focalizar, por exemplo, dois desses aspectos, contudo, para compreendê-los será necessário analisá-los com referência ao complexo processo de desenvolvimento que equivale à totalidade.

As pesquisas que temos desenvolvido ao longo dos últimos dez anos em escolas públicas brasileiras têm por objetivo estudar o desenvolvimento de crianças e jovens e o dimensionamento dos processos educativos em sua promoção. Por entender a escola como importante instituição na formação do ser humano e no caso do sujeito em específico, valorizar sua função privativa no ensino de conhecimentos complexos que impulsionam o desenvolvimento do pensamento por 
conceito, função primordial no favorecimento de formas mais ampliadas de consciência, temos tomado seus espaços como potentes às nossas investigações e ações interventivas.

Entretanto, a pesquisa na escola, em nossa compreensão, só se justifica se produzir, a um só tempo, transformações no modo de pensar e agir de estudantes e educadores, caracterizando-se como movimento contínuo de reflexão sobre questões levantadas pela comunidade escolar. É com essa premissa que nos inserimos na escola e permanecemos nela, pelo tempo em que demandas e reflexões forem sendo solicitadas e suscitadas.

Assim temos definido a pesquisa-intervenção, de natureza qualitativa e com características de pesquisa participativa:

[...] A intervenção é, a princípio, uma forma de acessar a realidade investigada e promover ações que permitam pôr o fenômeno em movimento. Entretanto, ao afetar o fenômeno que se modifica pelo fato mesmo de ser afetado, a intervenção põe em questão a investigação, transformando a própria pesquisa em vários e diversos níveis e dimensões. [...] Esse processo ocorre permanentemente, em uma relação dialética que ora evidencia a intervenção, ora a pesquisa, instituindo o caráter interdependente que ambas assumem nesta abordagem. Essa interpendência, ao se constituir como tal, assume dimensões contraditórias que só se revelam no ato mesmo de pesquisar-intervir. É unidade, uma vez que as ações de pesquisar e intervir são concomitantemente contraditórias e complementares, constituindo um processo em que ora a intervenção assume prevalência, quando a pesquisa sustenta as ações interventivas, e ora a pesquisa se constitui direcionadora das ações e a intervenção configura-se como condição ao seu desenvolvimento. (SOUZA; DUGNANI; REIS, 2018, p. 381)

Dessa perspectiva, a pesquisa-intervenção muda o lugar do pesquisador na ação e sua própria ação, que se configura também como prática psicológica e o coloca como produtor de significados e sentidos que devem ser considerados tanto na pesquisa como na reorganização e direcionamento da prática. Acreditamos que esse modo de pesquisar está em consonância com Vigotski (2004), ao defender que o método constitui-se a um só tempo como caminho e produto da pesquisa.

As ações que desenvolvemos na escola, que se constituem práticas interventivas e fontes de informação para as análises das pesquisas têm se utilizado de expressões artísticas como materialidade mediadora das reflexões que 
empreendemos com estudantes e profissionais ${ }^{6}$. E uma das razões de se utilizar a arte reside no fato de que as produções de natureza artística se erigem como plasmação da liberdade humana, muitas vezes para rechaçar a falta de liberdade a que estamos submetidos. E essa função de expressar seu contrário só se efetiva pela imaginação, que neste caso aparece em sua função libertadora e dialética. Essa compreensão também parece justificar a arte como instrumento psicológico e sua potência em fazer viver as emoções, conforme se afirma na citação a seguir:

[...] a arte, para atuar como instrumento psicológico, precisa confundir, paralisar, dificultar a percepção da realidade, produzir estranhamento. [...] A vivência da contradição é o que promove novas significações, superando a condição anterior de sentimento e pensamento, para, incorporando-os, construir novos nexos ou relações e ampliar a compreensão da realidade. (SOUZA; DUGNANI; REIS, 2018, p. 380)

Vigotski (1925/1999) entende a contemplação como um processo ativo em que o psiquismo atua em uma espécie de "curto-circuito" que repercute atividade intensa, em cuja base está o esforço de ressignificação do sujeito mobilizado pela vivência da contradição que emergiu pela apreciação estética.

É dessa natureza a experiência que apresento na discussão a seguir, a título de ilustração da potência da arte na promoção da imaginação em seu enlace com a emoção, entendendo-a como possibilidade de atuação do psicólogo na promoção do desenvolvimento em contextos coletivos. Desenvolvimento que se mantém como revolucionário, em permanente movimento direcionado ao futuro, criando devires.

\section{A potência da arte na promoção da imaginação: uma breve discussão}

As fotografias, cujas reproduções apreciadas pelos estudantes originou o texto da aluna que apresentamos a seguir, estão publicadas nos livros Êxodo (2000) e África (2007) de autoria do fotógrafo brasileiro Sebastião Salgado. Uma, mostra um campo de refugiados em Ruanda e consta da parte do livro Éxodos

\footnotetext{
${ }^{6}$ Para maiores informações sobre as bases teórico-metodológicas que sustentam nossas pesquisas, consultar o artigo: "Psicologia da Arte: fundamentos e práticas para uma ação transformadora", in: Estudos de Psicologia - Campinas, 2018; e demais artigos do tema especial sobre Psicologia da Arte, no mesmo volume.
} 
$(2000)^{7}$, denominada: "A tragédia africana: um continente à deriva”. A outra retrata um menino solitário, muito magro, olhando em direção a um horizonte em que se vê apenas uma terra deserta e seca, caminhando ao lado de um cachorro. Segundo o que descreve o fotógrafo, trata-se de garoto perdido de sua família após o massacre em Ruanda e consta do livro África (2007), em que explora o tema da desigualdade.

Após apresentar as reproduções aos alunos e empreender um processo de reflexão sobre o visto, mobilizada por questões como: - que emoções as imagens despertam; se retratam ou não a realidade, se sim, que realidade é esta; que motivações para essas ações, quais as consequências, dentre outras; apresentou-se aos estudantes informações sobre os locais fotografados, contextualizando a imagens historicamente, ampliando-se, assim, o conhecimento e a reflexão dos estudantes. Também foi apresentado o documentário "Sal da Terra", que retrata a vida do fotógrafo e examina o contexto de produção das fotografias cujas reproduções apreciaram. Em seguida, propôs-se aos estudantes que escrevessem, em grupo ou individualmente, um texto sobre essa experiência e, para fazê-lo, deveriam escolher um personagem e se colocar no lugar dele, que seria o narrador. A autora do texto a seguir trabalhou individualmente, e escolheu como personagem o garoto perdido em Ruanda.

[...] Havia um garoto muito determinado e corajoso que habitava Ruanda. [...] Sua vida era complicada, a miséria era sem tamanho. Doía. A fome doía. Ver sua família faminta doía. E ele não podia fazer nada quanto a isso. Porém, além da fome outra coisa o amedrontava e perturbava: a guerra, o ódio do ser humano, a disputa sangrenta por poder. [...] Um dia a maldade se aproximou dele mais do que nunca - um ataque à pequena região em que morava. [...] Ele perdeu-se de sua família durante o confronto. Solidão. Esta palavra ecoava em sua alma. A tristeza era gritante [...] o medo o soterrava. Ele olhou para o lado e viu um cachorro, tão perdido, faminto e solitário quanto ele. Então imaginou que seus pequenos e frágeis ombrinhos pareciam ter que carregar o mundo. Esse menino era eu. E essa foi a história de como o ódio do ser humano arrancou de mim, sem piedade, a

7 "Este livro [Êxodos] conta a história da humanidade em trânsito. É uma história perturbadora, pois poucas pessoas abandonam a terra natal por vontade própria. Em geral, elas se tornam migrantes, refugiadas ou exiladas constrangidas por forças que não têm como controlar, fugindo da pobreza, da repressão ou das guerras. [...] Viajam sozinhas, com as famílias ou em grupos. Algumas sabem para onde estão indo, confiantes de que as espera uma vida melhor. Outras estão simplesmente em fuga, aliviadas por estarem vivas. Muitas não conseguirão chegar a lugar nenhum." (SALGADO, 2000, p. 07). 
única coisa que eu tinha - minha família, o amor. Mas, de uma coisa eu tinha certeza: o ser humano, realmente, já estava perdido. Mais do que eu mesmo. (História produzida pela aluna T., 15 anos, $2^{\circ}$ Ano do Ensino Médio) ${ }^{8}$.

O que chama muito a atenção no excerto acima é a potência da imaginação para fazer viver as emoções e possibilitar que o sujeito acesse outros mundos, outras realidades, experimentando condições de vida que ele jamais imaginou.

No caso desta narrativa, a garota de quinze anos consegue se colocar no lugar do menino solitário que perdeu sua família, e, ao se colocar como este personagem ("como se"), passa a vivenciar suas emoções em um movimento que vai do individual - suas emoções, para o universal - o homem, a humanidade, passando pelo particular - o modo emocionado como vive a situação que, ao lermos o texto, nos convence que são delas os sentimentos. E o são, pois, para Vigotski (1925/1999), a intensidade e expressão da emoção vivida no cotidiano são diferentes daquelas desencadeadas pela apreciação de uma obra, de natureza estética: "não sofro com alguém, mas sofro porque o sofrimento do outro gera motivos para que eu coloque em movimento o meu próprio sofrimento" (p. 269). Para ele, os dois tipos de emoção são reais - a minha e a do personagem. A primeira vive em mim e a segunda - do personagem, além de ser vivida por mim na relação com a arte, coloca as minhas emoções em movimento.

E nós, ao lermos a narrativa emocionada de T., também nos emocionamos e é neste sentido que é possível afirmar a arte como instrumento psicológico de caráter mediatizante, pois, conforme afirma Manguel (2001, p. 32): “[...] cada obra de arte se expande mediante incontáveis camadas de leituras, e cada leitor remove essas camadas a fim de ter acesso à obra nos termos do próprio leitor. Nessa última (e primeira) leitura, nós estamos sós".

\footnotetext{
${ }^{8}$ Intervenção desenvolvida pela doutoranda Maura Assad Pimenta das Neves, como parte de seu projeto com alunos do $2^{\circ}$. ano do Ensino Médio em 2017. A estudante já acompanhava a turma desde o primeiro ano, com quem realizou atividades mediadas por música, filmes, biografias, e artes plásticas, além de realizar oficinas com profissionais escolhidos pelos estudantes sobre escolha profissional e profissões. A pesquisa de Maura tem sido apresentada em vários congressos e alguns recortes já foram publicados, a saber: SOUZA e NEVES (2019), Psicologia Escolar no Ensino Médio Público: O rap como Mediação; NEVES, ARINELLI, REIS, MEDEIROS e SOUZA (2018), Psicologia Escolar no Ensino Médio: reflexões sobre trabalho e profissão, e outros, estão em vias de publicação. Seu doutorado tem defesa prevista para fevereiro de 2020, devendo gerar novas socializações.
} 
Por se tratarem de fotografias que remetem a condições de vida precárias e por vezes subumanas, as emoções que emergem no sujeito que as apreciam ou mesmo em nós que somos "leitores dos leitores" são de natureza negativa, tais como tristeza, indignação, impotência. Se as fotografias fazem viver em nós essas emoções tristes, que como diria Espinosa (1677/1957) nos impingem o padecimento, no caso, resultado de nosso confronto com a impotência diante das situações e com a pior das dimensões do ser humano, expressões artísticas de outra natureza, como pinturas, por exemplo, do tipo surrealistas, suscitam outras camadas de significações, parecendo direcionar o pensamento ao futuro, ultrapassando os limites da realidade, o que só é possível por meio da imaginação.

Tomemos como o exemplo da apreciação por uma turma de alunos de uma pintura em aquarela do pintor italiano contemporâneo, Sergio Ricciuto Conte 9 , intitulada "O instrutor de coragem", que mostra um rapaz de frente para uma parede de tijolos onde se vê a projeção de uma escada. O desenho da escada parece ser uma sombra que começa no corpo do rapaz, da projeção de suas pernas. A apreciação resulta no seguinte diálogo entre os alunos:

"A sombra de uma escada."

"É uma sombra ali."

"Ahhh, eu acho que eu entendi. [...] Isso aqui é a sombra de uma escada e se você for ver é a sombra dele mesmo. É como se dependesse dele mesmo conseguir passar para o outro lado."

"Não, mas, pra ele conseguir, acho que o que tá representando a imagem, ele tá olhando pra baixo, ele tá vendo que pra ele conseguir subir ele vai precisar se esforçar, porque vai vir dele a escada, não vai adiantar nada ele ficar parado esperando."

"Por que ele quer subir esse muro?"

"Ele quer ver o outro lado, ver se tem algo melhor do outro lado. Ele quer melhorar a vida."

"Dar um passo a mais na vida dele. Pular uma barreira."

"Fora o fato de ele ser negro."

"Tem diferença?" [...]

"Pode ser algo de antigamente quando os negros sofriam mais preconceito. " [...]

"O muro é o próprio preconceito. Ele quer pular isso, ultrapassar isso. [...] (diálogo a partir da apreciação da reprodução da pintura com

\footnotetext{
${ }^{9} \mathrm{O}$ artista, residente no Brasil desde 2010, nasceu em Foggia, na Itália. Formado em artes, filosofia e teologia, Sérgio Ricciuto Conte produz obras surrealistas fantásticas em telas, aquarelas, arte para mosaicos, ilustrações para livros, revistas e jornais. Possui um site em que se pode apreciar suas obras, inclusive esta apresentada aos estudantes. (https://www.sergioricciutoconte.com.br, recuperado em 08 de outubro, 2019).
} 
alunos do $2^{\circ}$. Ano do ensino médio diurno, coordenado pela psicólogapesquisadora Maura Assad Pimenta das Neves, no ano de 2017).

No âmbito das funções psicológicas superiores é possível observar a ação da imaginação neste diálogo se materializando em um "como se" de natureza diferente daquele expresso diante das fotografias. Ele parece criar potência de ação, no caso, de pensamento, ao se projetar no rapaz parado, estático diante de um muro e fazêlo agir, pular o muro, sendo ele mesmo a escada. E fazê-lo porque do outro lado tem melhores condições de vida. Essa ação demanda esforço, por isso o rapaz está parado e cabisbaixo, está se preparando para empreender o esforço necessário à travessia do muro. Esforço que o libertará da condição em que vive, que permitirá ultrapassar os limites do eu, aliás, um limite já transgredido ao poder gerar a própria escada.

Valiosa metáfora da escada que sai do sujeito - uma nova camada de significação criada pelos estudantes em um movimento claro de produzir novas relações entre as funções psicológicas superiores, chegando à generalização que nasce da observação de uma imagem e da reflexão no e com o coletivo! Valiosa para pensar o desenvolvimento revolucionário, mas é preciso complementar esta escada e o próprio muro, instituindo o social como força motriz.

É isso que acreditamos que a Psicologia Histórico-Cultural pode favorecer nos espaços coletivos. E a imaginação é meio e fim, por se constituir em instrumento para penetrar a ética, a estética, a epistemologia e a ontologia.

\section{Considerações Finais}

Conforme anunciado na introdução, o objetivo deste artigo é defender o desenvolvimento como revolucionário tomando a imaginação como central em seu processo. Imaginação como função psicológica superior, que está na base das demais funções e opera em conjunto com elas, fazendo movimentarem-se as relações que produzem novas significações e possibilidades de ação e pensamento pelo sujeito. Sujeito revolucionário, portanto, pois dele emana a "escada/motivo" que suscita a ação de todo o sistema psicológico, como totalidade que constitui o homem, incorporando a cultura, as simbolizações de si, do outro, do mundo. Ação 
que movimenta o coletivo, interferindo nas ações dos outros no próprio processo de agir.

Desta perspectiva, também defende-se neste artigo a imaginação revolucionária, pela riqueza enorme de suas possibilidades, sobretudo de ignorar princípios e regras de pensamento e sentimento ao mesmo tempo que os aceita ou parte deles; de tolerar a coexistência de contrários no âmbito das imagens ou metáforas - como na animação dos objetos nas crianças; de encontrar identidade entre objetos e processos distantes; de fazer analogias como as metáforas poéticas; de criar situações e propor simulacros. Nesse movimento, opera com lógicas caracterizadas pela contradição, por antagonismos e incompatibilidades e, então, favorece o contraste, o surpreendente, o desconcertante, características que só emergem na experiência da contradição (LAPOUJADE, 1988, p.175).

É isso que vemos nas expressões dos estudantes que apresentamos no item anterior e que nos conduz à defesa da potência da arte em movimentar a imaginação no seu enlace com a emoção, favorecendo o desenvolvimento revolucionário. Potência que reporta à psicologia da arte preconizada por Vigotski com a ideia de reação estética favorecedora da catarse, a qual entendemos como expressão das emoções que a arte faz viver no sujeito graças à ação da imaginação. Imaginação que não atua sozinha, conforme já apontamos, mas em conjunto com outras funções, como a percepção, a memória, o pensamento, e as emoções. Logo, a vivência de expressões artísticas toma o sujeito como inteiro e a arte pode ser pensada como produção humana que sintetiza as características históricas e sociais da humanidade, que contém em sua forma e conteúdo a contradição, que é "como se" por simular situações do mundo que reportam ao humano. Logo, pode ser tomada como integradora do humano justamente por seu caráter revolucionário. (SOUZA; DUGNANI; REIS, 2018).

Temos clareza de que ainda há muito a se avançar nas ideias propostas neste texto no que concerne ao aprofundamento de suas bases epistemológicas e teóricas, sobretudo no adensamento do diálogo com outros campos de conhecimento, o que vimos tentando fazer há algum tempo. Entretanto, é preciso continuar o diálogo com outros pesquisadores, movimento característico da ciência cujo propósito mobilizou as reflexões aqui apresentadas. Esperamos que a tríade aqui proposta, 
qual seja, desenvolvimento revolucionário, imaginação revolucionária e arte suscite novas "camadas de significação", a exemplo do que ocorre quando nos confrontamos com nossa imagem, expresso no excerto abaixo, que tomamos emprestado como metáfora para finalizar este artigo.

Quando nos olhamos num espelho, pensamos que a imagem que temos diante de nós é exata. Porém, basta nos movimentarmos um milímetro e a imagem muda. Estamos olhando, na verdade, para uma infindável gama de reflexos. Mas às vezes um escritor precisa quebrar o espelho - pois é do outro lado do espelho que a verdade nos encara. Apesar das enormes variáveis existentes, creio que a determinação intelectual destemida, inarredável e feroz, como cidadãos, de definir a verdade real de nossas vidas e de nossa sociedade, é uma obrigação crucial, que cabe a cada um de nós. Ela é de fato imperiosa. Se essa determinação não estiver incorporada à nossa visão política, não teremos esperança de restabelecer o que está quase perdido para nós - a dignidade humana. (PINTER. Discurso do prêmio Nobel de literatura de 2005, apud MANGUEL, 2008)

\section{Referências}

CASSIRER, E. Antropologia Filosófica. São Paulo: Editora Mestre Jou, 1977.

ESPINOSA, B. Ética (3ª ed.). (L Xavier, Trans.). São Paulo: Atenas, 1677/1957.

LAPOUJADE, M. N. Filosofia de la imaginación. México: Siglo Veintiuno Editores, 1988.

MANGUEL, A. Lendo imagens: uma história de amor e ódio. São Paulo: Cia das Letras, 2001.

MANGUEL, A. À mesa com o Chapeleiro Maluco: ensaios sobre corvos e escrivaninhas. São Paulo: Cia das Letras, 2008.

NEVES, M. A. P.; ARINELLI, G. S.; REIS, E. C. G; MEDEIROS, F. P.; SOUZA, V. L. T. Psicologia Escolar no Ensino Médio: reflexões sobre trabalho e profissão. In: SOUZA, V. L. T.; AQUINO, F. de S. B.; GUZZO, R. S. L.; MARINHO-ARAÚJO, C. M. (org.). Psicologia Escolar Crítica: atuações emancipatórias nas escolas públicas. Campinas: Alínea, 2018, p. 83-100.

SALGADO, S. Exxodos. São Paulo: Companhia das Letras, 2000.

SALGADO, S. África. Colônia: Taschen, 2007. 
SOUZA, V. L. T. Arte, Imaginação e Desenvolvimento Humano; aportes à atuação do Psicólogo na escola. In: DAZZANI, M. V.; SOUZA, V. L. T. (org.) Psicologia Escolar Crítica: teoria e prática nos contextos educacionais. Campinas: Alínea, 2016, p. 77-94.

SOUZA, V. L. T.; DUGNANI, L. A. C.; REIS, E. C. G. Psicologia da Arte: fundamentos e práticas para uma ação transformadora. Estud. psicol. (Campinas), v. 35, n. 4, p. 375388, Dec. 2018

SOUZA, V. L. T.; NEVES, M. A. P. Psicologia Escolar no Ensino Médio Público: o rap como Mediação. Revista de Psicologia da IMED, Passo Fundo, v. 11, n. 1, p. 6-26, abr. 2019.

TATEO, L. What imagination can teach us about the higher mental functions. In: VALSINER, J.; MARSICO, G.; CHAUDHARY, N.; SATO, T.; DAZZANI, V. Psychology as the Science of human being. Annals of theoretical psychology: Springer, 2016, p. 149-164.

VERESOV, N. The concept of perezhivanie in cultural-historical theory: content and contexts. In: FLEER, M.; GONZÁLEZ-REY, F.; VERESOV, N. Perezhivanie, emotions and subjectivity, Perspectives in Cultural-Historical Research. Singapore, Springer, 2017. p. 47-70.

VIGOTSKI, L. S. Obras Escogidas (Lydia Kuper, Trad.). Madrid: Visor, 1995. (Trabalho original publicado em 1931). iii.

VIGOTSKI, L. S. Obras Escogidas (Lydia Kuper, Trad.). Madrid: Visor, 1996. (Trabalhos originais de 1930-1934). iv.

VIGOTSKI, L. S. Psicologia da Arte. São Paulo, Martins Fontes, 1999. (Texto original publicado em 1925).

VIGOTSKI, L. S. Teoria e método em psicologia. (C. Berliner, Trad.). São Paulo, Martins Fontes, 2004. (Textos originais de 1924-1934).

VIGOTSKI, L. S. La imaginacion y el arte en la infancia. Madrid: Akal, 2009. (Texto original publicado em 1930).

VIGOTSKI, L. S. Quarta aula: a questão do meio na pedologia. (MP Vinha, Trad.). Psicologia USP , 21, 681-701, 2010. (Trabalho original publicado em 1935). 